\title{
Screening for Glaucoma in the Community by Non- Ophthalmologically Trained Staff Using Semi Automated Equipment
}

\author{
S. A. VERNON, ${ }^{*}$ D. J. HENRY, $\dagger$ L. CATER, $\ddagger$ S. J. JONES $\dagger$ \\ Nottingham
}

\begin{abstract}
Summary
Eighty-nine and a half per cent of the population of a general practice over the age of 49 years were screened for glaucoma and high risk ocular hypertension requiring treatment. Screening took place using semi-automated intraocular pressure and visual field equipment operated by non-ophthalmologically trained staff. An experienced ophthalmologist examined all patients in a single blind manner to reduce false negatives to a minimum. Patients suspected of requiring treatment on the grounds of raised intraocular pressure, abnormal visual fields or suspicious optic discs were subsequently examined in a hospital clinic. Treatment criteria, as commonly practiced, were carefully defined and the sensitivities and specificities of the methods of screening used were calculated. One and three tenths per cent of the practice population were known to be receiving treatment prior to the study and a further $1.4 \%$ were found to require treatment after screening.

The sensitivity and specificity of the non-contact tonometer were $91.7 \%$ and $95.6 \%$ respectively with a predictive power of $22.5 \%$ for a positive result. The mean time taken to perform the test in both eyes was two minutes.

Seventy per cent of the patients with pressures over $22 \mathrm{mmHg}$ in both eyes on screening were found to require treatment. The routine use of the field screener did not increase either the sensitivity or specificity of the screening process but its use in cases with raised intraocular pressure is advised to indicate the degree of urgency of the referral.

An algorithm based on the results of the study is suggested when planning the use of semi-automated equipment to screen for ocular disease related to raised intraocular pressure.
\end{abstract}

Chronic Simple Glaucoma (CSG) is a common disease of middle age and the elderly, prevalence rising from $0.5-1 \%$ of the population over the age of $40^{1,2}$ to $6.6 \%$ over $75 .^{3}$ It is responsible for up to $16.8 \%$ of regis- trable blindness in the population of the United Kingdom aged over 65 years. ${ }^{4}$

CSG is characterised by a triad of physical signs: raised intraocular pressure (IOP), (generally considered greater than 21 
$\mathrm{mmHg}$, pathological cupping of the optic disc, and visual field defects of the nerve fibre bundle type. In most cases it is asymptomatic until advanced visual field loss has occurred and visual acuity is affected, by which time an estimated $90 \%$ of optic nerve fibres are lost. ${ }^{5}$ Glaucoma suspects account for $13 \%$ of referrals to a general ophthalmology clinic. ${ }^{6}$

It is still commonplace for patients to present to the Hospital Eye services for treatment with severe visual loss in at least one eye..$^{7-9}$ Most referrals are initiated by opticians. ${ }^{10}$

CSG has the characteristics of a disease for which screening is indicated. It is common, important, has a pre-symptomatic phase and effective treatments are available. The other essential criteria are a diagnostic test or tests which are cheap, acceptable, sensitive and specific. Until now, no reports of glaucoma screening programmes using such tests have been described.

Many opticians screen their clients over the age of 40 years for glaucoma but their methods and indications for referral have been shown to vary considerably. ${ }^{11}$ The sensitivity and specificity, of the optometrist-based screening service is uncertain as their false negative rate is unknown.

Methods of detecting glaucoma in common use are tonometry, visual field analysis and optic disc examination. Direct applanation tonometry (DAT), as used in hospital clinics, requires the instillation of drops which may be perceived as unpleasant, and has a low sensitivity. ${ }^{12}$ Manual perimetry is time consuming and non-specific. ${ }^{13,14}$ Disc examination, the method advocated for glaucoma screening by one authority, ${ }^{15}$ is prone to error even in the hands of experienced observers. ${ }^{16}$

We therefore designed a pilot study to try to overcome these deficiences.

Intraocular pressure measurements without direct contact of an instrument with the eye have been possible for over 15 years ${ }^{17}$ and are used by many opticians. These 'non-contact tonometers' (NCT) work by measuring the change in reflection of light from the cornea following a calibrated jet of air. The 'Pulsair' NCT, recently introduced, uses only $50 \%$ of the pulse pressure of previous instruments to obtain a reading. It has been shown to correlate well with Goldmann DAT and is well tolerated by patients. ${ }^{18,19}$ Visual fields can also be assessed rapidly using computerised analysers which compare well with manual methods. ${ }^{20,21}$

Our study assesses the feasibility of screening for glaucoma in the community by nonophthalmologically trained staff using such equipment. The study also aimed to determine the proportion of patients requiring treatment that were known to the Hospital Eye Service before changes in the eye test regulations were implemented.

\section{Method}

Using a computer, patients in a general practice over 49 years of age were identified and invited, by letter, to attend a screening session. Patients already known to have glaucoma were excluded along with known cases of dementia and those registered blind. The invitation explained the nature of the tests that would be used. An appointment time was given and patients had the opportunity to change this if it was inconvenient.

In order to reduce false negatives to a minimum, the protocol included tonometry, visual field analysis and optic disc assessment in every case.

At the screening clinic the IOP in each eye was measured by taking the mean of four readings with the 'Pulsair', a handheld NCT. All IOP readings in the study were taken by one operator (LC). The central visual field of each eye was then assessed using the Henson CFS2000 field screener. A standard protocol required the test to be performed either with single vision reading spectacles or unaided. The minimum vision required to perform the test was defined as the ability to see the central fixation target. Central thresholds were then determined for each eye and the 26 point suprathreshold screening programme was run. A missed point on this test required the operator to extend to a 66 point test, determining the level of sensitivity loss at each point. A failed test was defined as occurring when sufficient points had been missed to drop the indicator on the screen into the suspicious zone or below. ${ }^{22}$

Patients had their visual acuities measured using a standard Snellen chart with distance correction plus or minus pin hole if required. 
Table I Sensitivity, specificity and predictive powers of screening tests

\begin{tabular}{|c|c|c|c|c|c|c|c|c|}
\hline Test & $\begin{array}{c}\text { Test } \\
\text { incomplete }\end{array}$ & $N E G$ & $P O S$ & $R x$ & $S E N S \%$ & $S P E C \%$ & $P V+v e \%$ & $P V-v e \%$ \\
\hline$P$ & 0 & 825 & 49 & 11 & 91.7 & 95.6 & 22.5 & 99.9 \\
\hline $\mathrm{H}$ & 19 & 822 & 33 & 3 & 25 & 91.7 & 9.1 & 98.9 \\
\hline $\mathrm{P}+\mathrm{H}$ & 19 & 781 & 74 & 11 & 91.7 & 92.5 & 14.9 & 99.9 \\
\hline D & 38 & 836 & 18 & 7 & 58.3 & 98.7 & 38.9 & 99.4 \\
\hline
\end{tabular}

$\mathrm{n}=874$, Treatment required in 12

$\mathrm{P}=$ Pulsair, $\mathrm{H}=$ Henson CFS2000, $\mathrm{D}=$ Ophthalmologist disc assessment, $\mathrm{P}+\mathrm{H}=$ results considering a fail in either test to be significant, $\mathrm{NEG}=$ number with negative test, $\mathrm{POS}=$ number with positive test, $\mathbf{R x}=$ number with positive test requiring treatment, SENS $\%=$ sensitivity expressed as a percentage, SPEC $\%=$ specificity expressed as a percentage, $\mathrm{PV}+\mathrm{ve} \%=$ predictive power of a positive test as a percentage, $\mathrm{PV}-\mathrm{ve} \%=$ predictive power of a negative test as a percentage.

All patients then had their optic discs graded by an experienced ophthalmologist (SAV) using a direct ophthalmoscope through undilated pupils. This arm of the study aimed to simulate the 'ideal' monocular disc screening that could be expected in either general practice or by an optometrist.

Discs were graded, without knowledge of the other two results, as normal or suspicious. A disc was considered suspicious if one of the following features was judged to be present-

(1) Focal or diffuse pallor of the neuroretinal rim.

(2) Vertical cup-disc ratio $>0.7$.

(3) Focal notching of the rim.

(4) Asymmetry of 0.2 or more in the cup-disc ratio.

(5) 'Nasalisation' of the retinal vessels as they cross the disc rim.

(6) Disc haemorrhage.

Where an abnormal field occurred in the absence of raised IOP or a suspicious disc, the ophthalmologist attempted to ascertain the reason for the defect by further examination of the fundus.

All patients with a mean IOP of $>22 \mathrm{mmHg}$ in an eye, a suspicious disc, or unexplained field loss were given an appointment to attend a hospital glaucoma clinic where the following ophthalmological assessment was made.

(1) Goldmann applanation tonometry, (initial tonometer reading set at $10 \mathrm{mmHg}$ and adjusted upwards to neutralisation prior to visualisation of the scale).

(2) Friedmann Mk 1 visual field analysis.

(3) Gonioscopy with three dimensional disc assessment.

The following criteria were used in the glau- coma clinic to define eyes which required treatment:

Group 1: IOP $>22 \mathrm{mmHg}$ plus pathologically cupped disc with field loss ie classical CSG.

Group 2: IOP $>22 \mathrm{mmHg}$ on two hospital visits in association with two or more of the pathological disc parameters $1-6$ outlined above despite normal fields.

Group 3: IOP $>30 \mathrm{mmHg}$ on two hospital visits.

\section{Results}

Fourteen patients with CSG or ocular hypertension under treatment were identified from the records of the 1070 patients aged 50 and over in the practice, ie a known prevalence of $1.3 \%$.

Of the 988 patients in the practice who were invited, $874(88.5 \%)$ attended, 813 following the initial invitation and 61 following a reminder. Three hundred and seventy-four of the attenders were males (43\%) and 500 were females $(57 \%)$. The mean age of attenders was 65 years. Non attenders did not differ significantly from attenders by age, sex, known hypertension, known diabetes or known family history of glaucoma.

When questioned, 587 attenders $(67 \%)$ had been aware that glaucoma was an eye disease before receiving the invitation, 127 (15\%) remembered being tested for glaucoma previously, most by an optician, and 39 (4\%) knew of glaucoma in a first degree relative. Twenty-eight patients (3\%) were known to be diabetic.

Twelve patients ( $1.4 \%$ of those tested) were identified as requiring treatment for raised 
Table II Failure to perform field test

\begin{tabular}{lc}
\hline Cause & $\begin{array}{c}\text { No of } \\
\text { patients }\end{array}$ \\
\hline Cataract & 7 \\
Macular disease & 5 \\
High refractive error & 1 \\
Retinal detatchment & 1 \\
Foster Kennedy syndrome & 1 \\
Newly diagnosed glaucoma & 1 \\
Amblyopia & 1 \\
Homonomous hemianopia & 1 \\
Poor attention span & 1 \\
Total & 19 \\
\hline
\end{tabular}

IOP following at least one hospital visit. There were four in each of our diagnostic groups. Only one patient was identified as suffering from low tension glaucoma. Two of the $12(17 \%)$ were diabetic and four $(33 \%)$ had a positive family history of glaucoma.

The prevalence of CSG and ocular hypertension requiring treatment in this population of mean age 65 was therefore $2.7 \%$.

For further analysis, data will be presented in terms of patients failing a test in either eye. Sensitivity, specificity and predictive powers are calculated assuming a true positive is a patient who requires treatment. Table I compares the results of each screening method. In the case of the Henson, the calculations assume any field abnormality not due to glaucoma to be a false positive.

\section{(a) IOP measurements with the Pulsair}

All 874 patients who attended had four IOP readings per eye with the Pulsair. The time taken to perform the eight readings averaged two minutes per patient.

In the 1748 eyes tested, the mean IOP was $14.96 \mathrm{mmHg}$ with a standard deviation of $3.29,98 \%$ confidence limits $14.77-15.15$.

Forty-nine patients $(5.6 \%)$ had a raised IOP, defined as a mean IOP of $>22 \mathrm{mmHg}$, in one or both eyes. Of these 49 patients, eleven were later defined as requiring treatment. Ten were confirmed as having ocular hypertension for whom treatment was not indicated and 15 had no abnormality at the hospital visit. Thirteen very elderly or infirm patients with unequivocally normal discs and fields did not attend the hospital and were considered not to require treatment for the purposes of the study. One further patient was found to need treatment when a raised IOP in combination with a pathologically cupped disc was determined at the hospital visit.

Of the eleven patients identified by the Pulsair and later found to require treatment, seven had IOPs $>22 \mathrm{mmHg}$ in both eyes on screening. Only three of the 38 patients determined not to require treatment had bilaterally raised IOPs initially $(0.01>p>0.001$ by $\mathrm{Chi}$ squared analysis).

\section{(b) Henson CFS 2000 Field analysis}

Nineteen patients $(1.43 \%)$, mean age 74.4 , were unable to complete the field test in both eyes. The reasons for these failures are shown in Table II. The only patient with good acuity who could not perform the test was very elderly and suffered from poor attention.

The time taken to perform fields in both eyes if neither eye required an extended test ranged from 1 minute 40 seconds to 4 minutes 5 scconds with a mean of 2 minutes 30 seconds. This included a 30 second explanation for each patient.

Ninety-eight patients $(11.5 \%)$ had an extended test. The fields from 65 of these patients (mean age 62.3) did not fall into the suspicious range on the Henson. Thirty three patients, mean age $72.3,(3.86 \%$ of all patients tested) failed the test. The cause of the field defects which resulted in a failed test are shown in Table III.

The mean time taken to perform fields if an extended test was necessary was three minutes for a single extension and five minutes if both eyes required extension.

Table III Failure to pass field test

\begin{tabular}{lc}
\hline Cause of field loss & $\begin{array}{c}\text { No of } \\
\text { patients }\end{array}$ \\
\hline Neurological & 9 \\
Macular scarring & 7 \\
False positive & \\
(no cause found) & 4 \\
Glaucoma & 3 \\
High Myopia & 3 \\
Branch vein occlusion & 2 \\
Diabetic retinopathy & 1 \\
Retinal detachment & 1 \\
Cataract & 1 \\
Intra ocular foreign body (old) & 1 \\
Amblyopia & 1 \\
Total & 33 \\
\hline
\end{tabular}


Table IV Reasons for failure to assess disc

\begin{tabular}{lc}
\hline Cause of failure & $\begin{array}{c}\text { No of } \\
\text { patients }\end{array}$ \\
\hline Cataract & $28(6)$ \\
High myopia & 4 \\
Post cataract surgery & 2 \\
Miotic pupils & 1 \\
Corneal scar & 1 \\
Unco-operative patient & 1 \\
Retinal detachment & $1(1)$ \\
Total & $38(7)$ \\
\hline
\end{tabular}

Note 7 patients overlap with Table II (shown in parentheses).

Three patients with abnormal Henson fields were confirmed as having glaucomatous field loss with the Friedmann. One other patient was later shown to have glaucomatous field loss. The eye had required an extended field on the Henson but had not fallen into the suspicious range. No other false negatives were found following the hospital assessment.

\section{(c) Disc examination}

This arm of the study was designed to reduce false negatives of the overall study to the minimum. However, in 38 patients $(4.4 \%)$ a satisfactory assessment of both discs could not be made. Table IV indicates why the ophthalmologist failed to assess this group.

Eighteen patients were detected as having suspicious discs when the ophthalmologist applied criteria for glaucomatous change. Seven were confirmed as possessing at least one eye in diagnostic groups 1 or 2 following the hospital assessment. The remaining eleven patients all had normal fields and IOPs at both the screening and the glaucoma clinics.

Five patients now on treatment were not identified by the 'blind' disc examination. Four of these constituted the patients in treatment group 3.

\section{(d) IOPs and Fields}

Seventy-four $(8.5 \%)$ of patients screened had a positive screen for either IOP or field. All but one of the 12 patients found to require treatment were identified.

\section{Discussion}

As far as we are aware, this study is the first to report the results of a glaucoma screening project based on a representative sample of the middle aged and elderly, which attempted to perform all three standard diagnostic tests in every case.

Abnormalities in tests of visual function or in the anatomy of the nerve fibre layer and optic nerve head are known to precede field loss in raised IOP. ${ }^{23-30}$ Raised IOP has been shown to be one of the most important prognostic indicators of future field loss. ${ }^{31-33}$ Indeed, it has been estimated that $50 \%$ of the nerve fibres in the optic nerve can be lost before any change in the visual field is detectable. ${ }^{5}$ Ophthalmologists are therefore advising treatment before field loss becomes apparent in cases where the IOP is sufficiently raised, or a pathological disc appearance is associated with an IOP $>22 \mathrm{mmHg} .{ }^{34-37}$

Evidence points towards treatment being of advantage in eyes with established field loss and raised IOP ${ }^{38,39}$ and therefore a system of detecting patients with such loss, or at risk of developing it, would seem desirable.

In a large scale epidemiological study in Wales performed during the early 1960 s, $50 \%$ of CSG cases in a community had been identified prior to the screening study. ${ }^{1}$ Twenty-five years later our study shows the situation to be unchanged despite the increasing trend for opticians to screen for glaucoma. The effect of the recent Government proposals on glaucoma detection remains to be seen, but our study would indicate that there is scope for improvement even to the present system.

An effective screening programme should. satisfy certain well defined criteria. ${ }^{12} \mathrm{~A}$ discussion of the intrinsic merits of a glaucoma screening programme is outside the scope of this paper but a few points deserve mention in the light of our results.

The efficiency of a screening test is judged by its sensitivity, a measure of false negatives, and by its specificity, a measure of false positives. When the prevalence of a condition is as low as $2 \%$, high degrees of sensitivity and specificity must be attained to produce sufficiently high predictive powers of positive and negative tests. ${ }^{12}$

Evaluation of sensitivity and specificity depend on the definition of abnormality and a certainty that the true status is known for each 
subject. Glaucoma screening studies are plagued by the possibility of false negatives. Although theoretically it would have been preferable to perform a three-dimensional assessment of every disc with a dilated pupil using a slit lamp, this was considered impractical in such a screening study. The high uptake rate observed may have been due to the assurance in the letter of invitation that no drops or tests that disturbed vision would be performed.

We have chosen to apply current treatment criteria in our definition of a true positive test. Thus the sensitivity and specificity of the Pulsair appear higher than the figures calculated from other epidemiological studies. ${ }^{12}$ These studies used DCTs and insisted on established field loss as a 'sine qua non' of the disease state.

In the Ferndale study ${ }^{1}$ a positive case was defined as a pathologically cupped disc with glaucomatous field loss and DCT was used. The sensitivity of DCT was $50 \%$ in this study. If we apply these criteria to our study, the sensitivity of the Pulsair NCT is $80 \%$. True 'low tension' glaucoma, however, accounts for only about $10 \%$ of a glaucoma clinic population. ${ }^{40}$ Diurnal and longer term IOP fluctuations have been cited as possible explanations for low DCT sensitivities. ${ }^{41}$

The repeated low sensitivity of DCT in epidemiological studies has undoubtedly compromised the development of glaucoma screening programs.

The Pulsair NCT has been shown to correlate well with the Goldmann $\mathrm{DCT}^{18,19}$ and mean IOPs found in population studies, using DCT such as the Goldmann ${ }^{42,43}$ equate well with our figure of $14.96 \mathrm{mmHg}$. $5.6 \%$ of our patients recorded an IOP of $>22 \mathrm{mmHg}$ in an eye, ie an IOP two standard deviations above our mean. We chose to consider a reading of over $22 \mathrm{mmHg}$ as an indication for further investigation but analysis of our results reveals that all but one of the eleven patients now on treatment would have been identified if we had used a reading of $>23 \mathrm{mmHg}$ as significant. Even at this level sensitivity remains high at $82 \%$ and does not drop to $50 \%$ until a level of greater than $26 \mathrm{mmHg}$ is set.

Thus the Pulsair appears to be significantly more efficient at detecting those patients with raised IOP requiring treatment while at the same time returning a similar prevalence of patients with pressures $>22 \mathrm{mmHg}$. A number of factors may be involved; the Pulsair measures IOP by sampling the ocular pulse at a moment in the cardiac cycle whereas a contact applanation device damps the pulse, taking a 'mean' reading. It has been demonstrated that the ocular pulse amplitude is greater in those with glaucoma. ${ }^{44}$ As we used four readings per eye to produce our mean, random sampling with the Pulsair may produce a higher mean in those prone to IOP related damage than in normal subjects with IOP around $20 \mathrm{mmHg}$ or in those with benign 'ocular hypertension'.

Operator bias is eliminated with the Pulsair since it produces a digital readout. Using the Goldmann DCT, a reading must be taken from a scale after a visual assessment of 'neutralisation' and such measurements are subject to operator bias. ${ }^{45}$ After repeated measurements with the Goldmann, readings have been shown to reduce by an average of $3 \mathrm{mmHg}^{46}$ NCTs do not share this characteristic. ${ }^{44}$

Although the number of subjects in our study is smaller than in other reported series, we believe the results suggest that NCT using a mean of four readings per eye should be considered as the first line screening test to identify those at risk of IOP related disease.

We do not consider field analysis to be effective as a first line screening tool for glaucoma in the community despite its ease of use and speed. The predictive power of a positive test applying our criteria for treatment $(9.1 \%)$ does not compare favourably with the predictive power of the Pulsair $(22.5 \%)$. However, if field analysis is limited to patients with an IOP $>22 \mathrm{mmHg}$ as measured with the NCT, it may be used prior to referral to determine the degree of urgency.

The predictive power of direct ophthalmoscopy by the ophthalmologist in detecting patients in need of treatment was greater than either the NCT or the field analyser used separately or in combination. His sensitivity, however, was over $30 \%$ lower than the NCT. This indicates that, even if non-ophthalmologists could be trained to a similar standard, a high false negative rate would occur. 


\section{Algorithm for Glaucoma Screenings}

IOP measurement taking mean of 4 readings per eye

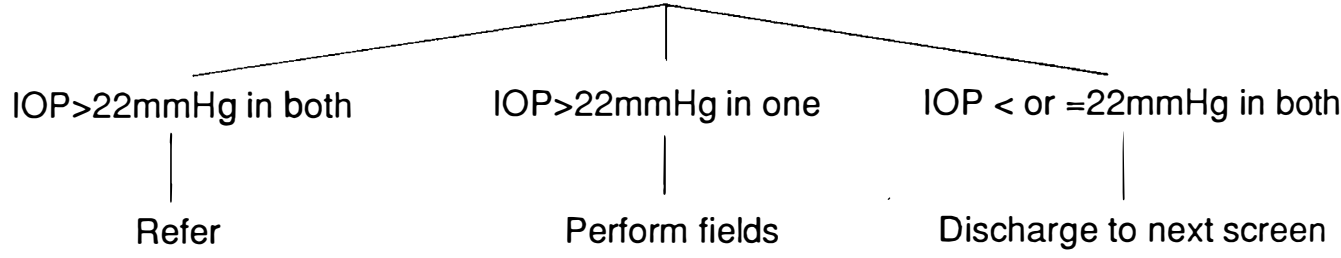

(70\% chance of requiring treatment even if field normal in our study)

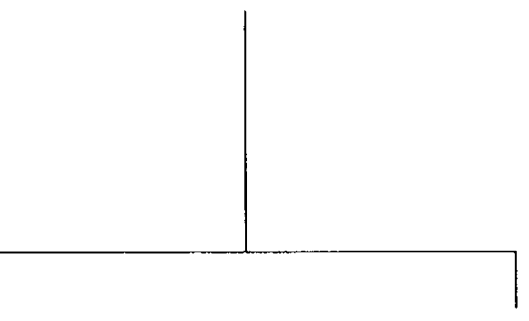

If either field $+\mathrm{ve}$<smiles>C1CCCCC1</smiles>

Refer

If both fields -ve

(100\% chance of requiring treatment in our study)

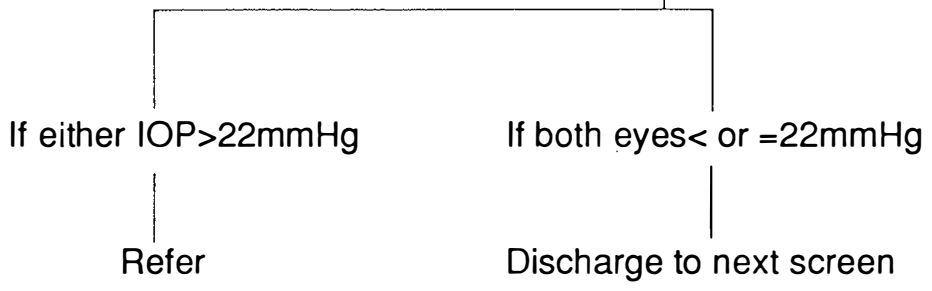

(probably ocular hypertension

but $20 \%$ chance of requiring treatment in our study)

Fig. 1. Algorithm for community based glaucoma screening.

Patients in this practice demonstrated their willingness to be subjected to glaucoma screening by their high attendance rate. Many had been invited to participate in other screening exercises in the past including colo- rectal screening and mammography, for which uptake rates of $62 \%$ and $77.5 \%$ had been recorded.

The practice is considered to be representative of the population of England and Wales in 
terms of its age distribution. The uptake rate of $88.5 \%$ observed in this study may be a good omen for future glaucoma screening projects.

An analysis of the cost-effectiveness of the systems used in this study will be the subject of another report. We were encouraged by the speed of IOP testing with the Pulsair NCT and the $100 \%$ compliance with the test, all patients completing a full set of eight readings.

Preventive medicine has been allocated a high priority by the present Government and demand for screening under the NHS is growing. In the over $65 \mathrm{~s}$, glaucoma is only exceeded by senile macular degeneration (SMD) as a cause of registerable blindness. ${ }^{47}$ Patients with SMD retain peripheral field and therefore navigational vision, whereas those registered blind from glaucoma have usually lost both central and peripheral vision. Once registered, a patient has been estimated to have ten years of blindness ahead of him. ${ }^{48}$

From 1 April 1989, the only patients entitled to a free glaucoma test by an optician on medical grounds are diabetics, those with a positive family history of glaucoma and those already registered partially sighted or blind. In our study, only $42 \%$ of patients found to require treatment were known diabetics and/or had a positive family history of glaucoma. This reinforces the clinical impression that most patients in a glaucoma clinic have neither of these risk factors. Limiting screening to these high risk groups may miss over $50 \%$ of persons with the disease.

Our study suggests that mass glaucoma screening can be performed with satisfactory levels of sensitivity and specificity using noninvasive equipment operated by staff with no formal eye training providing a strict protocol is observed.

As a result of our pilot study, we suggest an algorithm for use by such staff to screen an asymptomatic population age 50 years and over for raised IOP requiring treatment (Fig. 1).

This study was supported by grants from the International Glaucoma Association and MSD Ltd. The Pulsair NCT and Henson CFS2000 were kindly loaned by Keeler Ltd. The authors have no financial interest in any of the aforementioned companies or the semiautomated equipment.

\section{References}

${ }^{1}$ Hollows FC and Graham PA: Intraocular pressure, glaucoma and glaucoma suspects in a defined population. Br J Opthalmol 1966, 50: 570-86.

${ }^{2}$ Bengtsonn B: The prevalence of glaucoma. $\mathrm{Br} J$ Ophthalmol 1981, 65: 46-9.

${ }^{3}$ Gibson JM, Rosenthal AR, Lavery J: A study on the prevalence of eye disease in the elderly in an English Community. Trans Ophthalmol Soc UK 1985, 104: 196-203.

${ }^{4}$ Ghafour IM, Allan D, Foulds WS: Common causes of blindness and visual handicap in the West of Scotland. Br J Ophthalmol 1983, 67: 209-13.

${ }^{5}$ Quigley HA, Addicks EM, Green WR: Optic nerve damage in human glaucoma. III Quantitative correlation of nerve fibre loss and visual field defect in glaucoma, ischaemic neuropathy, papilledema and toxic neuropathy. Arch Ophthalmol 1982, 100: $135-46$.

${ }^{6}$ Harrison RJ, Wild JM, Hobley AJ: Referral patterns to an ophthalmic outpatient clinic by general practitioners and ophthalmic opticians and the role of these professionals in screening for ocular disease. Br Med J 1988, 297: 1162-7.

${ }^{7}$ Pitts Crick R: Chronic glaucoma-A preventable cause of blindness. Lancet 1974, 1: 205-7.

${ }^{8}$ Steinmann WC: The 'who' and 'how' of detecting glaucoma. Br Med J 1982, 285: 1091-3.

${ }^{9}$ MacKean JM and Elkington AR: Referral rates to hospital of patients with chronic open angle glaucoma. Br Med J 1982, 285: 1093-5.

${ }^{10}$ Brittain GPH, Austin DJ, Kelly SP: A prospective survey to determine sources and diagnostic accuracy of glaucoma referrals. Health Trends 1988, 20: $43-4$.

${ }^{11}$ Vernon SA and Henry DJ: Do optometrists screen for glaucoma? Eye (in press).

${ }^{12}$ Leske MC and Hawkins BS: Screening: relationship to diagnosis and therapy. In: Clinical Ophthalmology (Duanne TD, Jaeger EA, ed.) Philadelphia, Harper and Row. 1987, 3(54): 1-16.

${ }^{13}$ Trobe JD, Acosta PC, Shuster JJ, Krischer JP: An evaluation of the accuracy of community based perimetry. Am J Ophthalmol 1980, 90: 654-60.

${ }^{14}$ Rock WT, Drance SD, Morgan RW: Visual field screening in glaucoma-an evaluation of the Armaly technique for screening glaucomatous visual fields. Arch Ophthalmol 1973, 89: 287-90.

${ }^{15}$ Hitchings RA: Screening for glaucoma. Br Med J 1986, 292: 505-6.

${ }^{16}$ Klein BEK, Moss SE, Magli YL, et al. Optic disc cupping as clinically estimated from photographs. Ophthalmology 1987, 94: 1481-3.

${ }^{17}$ Grolman B: A new tonometer system. Am J Optom and Arch Am Acad Optom 1972, 49: 646-60.

${ }^{18}$ Fisher JH, Watson PG, Spaeth G: A new handheld air impulse tonometer. Eye 1988, 2: 238-42.

${ }^{19}$ Vernon SA: Non-contact tonometry in the postoperative eye. Br J Ophthalmol 1989, 73: 247-9.

${ }^{20}$ Hotchkiss ML, Robin AL, Quigley HA, Pollack IP: A comparison of peritest automated perimetry and Goldmann perimetry. Arch Ophthalmol 1985, 103: 397-403. 
${ }^{21}$ Batko KA, Anctil JL, Anderson DR: Detecting glaucomatous damage with the Friedmann analyser compared with the Goldmann perimeter and evaluation of stereoscopic photographs of the optic disc. Am J Ophthalmol 1983, 95: 435-47.

${ }^{22}$ Henson CFS2000 Central Field Screener-operating instructions 1988. Keeler Ltd., Windsor Berks.

${ }^{23}$ Ross JC, Bron AJ, Reeves BC, Emmerson PG: Detection of optic nerve damage in ocular hypertension. Br J Ophthalmol 1985, 69: 897-903.

${ }^{24}$ Pederson JE and Anderson DR: The mode of progressive disc cupping in ocular hypertension and glaucoma. Arch Ophthalmol 1980, 98: 490-5.

${ }^{25}$ Airaksinsen PJ, Drance SM, Douglas GR, Schulzer M, Wijsman K: Visual field and retinal nerve fibre layer comparisons in glaucoma. Arch Ophthalmol 1985, 103: 205-7.

${ }^{26}$ Balazsi AG, Drance SM, Schulzer M, Douglas GR: Neuroretinal rim area in suspected glaucoma and early chronic open angle glaucoma. Correlation with parameters of visual function. Arch Ophthalmol 1984, 102: 1011-14.

${ }^{27}$ Weinstein GW, Arden GB, Hitchings RA, Ryan S, Calthorpe CM, Odom JV: The pattern electroretinogram (PERG) in ocular hypertension and glaucoma. Arch Ophthalmol 1988, 106: 923-8.

${ }^{28}$ Gunduz K, Arden GB, Peery S, Weinstein GW, Hitchings RA: Colour vision defects in ocular hypertension and glaucoma. Arch Ophthalmol 1988, 106: 929-35.

${ }^{29}$ Wanger $\mathrm{P}$ and Persson HE: Pattern electroretinograms and high pass resolution perimetry in suspected or early glaucoma. Ophthalmology 1988, 95: 1098-103.

${ }^{30}$ Nanba K and Schwartz B: Nerve fibre layer and optic disc fluorescein defects in glaucoma and ocular hypertension. Ophthalmology 1988, 95: 1227-33.

${ }^{31}$ Kass MA, Kolker AE, Becker B: Prognostic factors in glaucomatous visual field loss. Arch Ophthalmol 1976, 94: 1274-6.

${ }^{32}$ Armaly MF, Kreuger DE, Maunder L, Becker B: Biostatistical analysis of the Collaborative Glaucoma Study. (1) Summary report of the risk factors for glaucomatous visual field defects. Arch Ophthalmol 1980, 98: 2163-71.
${ }^{33}$ Lewis JM, Priddy T, Judd J, et al.: Intraocular pressure response to topical dexamethasone as a predictor for the development of primary open angle glaucoma. Am J Ophthalmol 1988, 106: 607-12.

${ }^{34}$ Smith RJH: Ocular hypertension. Res Clin Forum 1980, 2: 129-31.

${ }^{35}$ Mills KB: Ocular hypertension. Res Clin Forum 1985, 7: 81-4.

${ }^{36}$ Goldmann $\mathrm{H}$ : An analysis of some concepts concerning chronic simple glaucoma. Am J Ophthalmol 1975, 80: 409-13.

${ }^{37}$ Drance SM: When to advise medical treatment for open angle glaucoma. Eye 1987, 1: 43-4.

${ }^{38}$ Grant WM and Burke JF: Why do some people go blind from glaucoma? Ophthalmology 1982, 89: 991-8.

${ }^{39}$ Jay JL and Murray SB: Early trabeculectomy versus conventional management in primary open angle glaucoma. Br J Ophthalmol 1988, 72: 881-9.

${ }^{40}$ Hitchings RA: Low tension glaucoma-is treatment worthwhile? Eye 1988, 2: 636-40.

${ }^{41}$ S mith J: Diurnal intraocular pressure-correlation with automated perimetry. Ophthalmology 1985 , 92: 858-61.

${ }^{42}$ David R, Zangwill L, Stone D, Yassur Y: Epidemiology of intraocular pressure in a population screened for glaucoma. Br J Ophthalmol 1987, 71: 766-71.

${ }^{43}$ Graham P and Hollows FC: Sources of variation in tonometry. Trans Ophthalmol Soc UK 1964, 84: 597-613.

${ }^{44}$ Piltz JR, Starita R, Miron M, Henkind P: Momentary fluctuations in intraocular pressure in normal and glaucomatous eyes. Am J Ophthalmol 1985, 99: 333-9.

${ }^{45}$ Brubaker RF: Tonometry-In: Clinical Ophthalmology. (Duane TD, Jaeger EA, ed.) Philadelphia, Harper and Row 1987, 3(47): 1-7.

${ }^{46}$ Wilke K: Effects of repeated tonometry: genuine and sham measurements. Acta Ophthalmol 1972, 50: $574-82$.

${ }^{47}$ Aclimandos WR and Galloway NR: Blindness in the city of Nottingham (1980-85). Eye 1988, 2: 431-4.

${ }^{48}$ Green JS, Bear JC, Johnson GJ: The burden of genetically determined eye disease. Br J Ophthalmol 1986, 70: 696-9. 